\title{
Modeling and simulation of intermittent drying of high moisture foods
}

\author{
Filippin, A.P. ${ }^{a}$; Tada, E.F.R..$^{a}$; Thomeo, J.C. ${ }^{a}$; Mauro, M.A. ${ }^{{ }^{*}}$ \\ a UNESP - São Paulo State University, Institute of Biosciences, Humanities and Exact Sciences \\ (IBILCE), São José do Rio Preto, SP, Brazil
}

*Corresponding author: cidam@ibilce.unesp.br

\begin{abstract}
This study aimed at the modeling and simulation of intermittent drying to be applied to highly deformable moist foods such as apples. Mass transport modeling considered two stages: the first at 95, 85 and $75^{\circ} \mathrm{C}$ air temperatures, and the second at $60^{\circ} \mathrm{C}$. The shrinkage was correlated with the sample moisture and included in the model that was solved by the finite differences method. The first stage temperatures affected the water diffusivity in the second stage. This model was suitable for simulating the water profiles during the twostage intermittent drying, showing an efficient fitting to the experimental data.
\end{abstract}

Keywords: thermal intermittence; coefficient diffusion effective; shrinkage; apple drying. 


\section{Introduction}

Drying is an antique unit operation widely used by the food industry and it is based on moving of water from high to low moisture zones until reach a frontier and to be removed in the form of vapor. This operation favors the stability of the foods because it increases their shelf life due to the considerable decrease in the water activity of the material [1-3]. However, the energy demand of the drying operation is very high and besides that, can promote undesirable nutritional and organoleptic losses.

The recent literature has reported the intermittent drying processes as an alternative to decrease these negative impacts and to minimize energetic costs [4,5]. Intermittent drying consists in changing of the operational conditions during drying. In the case of the temperature variation during the process, referred as thermal intermittence, a high temperature is used in the beginning of the process favoring the evaporation. During this period the surface of the product is saturated and the water evaporation ensures its low temperature [6]. When instauration zones begin to appear on the surface, the drying air temperature is reduced.

The knowledge and control of the heat and mass transfer phenomena during drying is fundamental to establish process conditions that promote improvement in the quality of the product. In the case of variable process conditions, such as in the intermittent drying, the recent literature [4] has reported the necessity of intense investigation and understanding of the moisture and temperature evolution during the whole process. Mathematical models can be used to estimate physical and transport parameters, and to predict spatial and temporal moisture and temperature profiles. However, it is necessary that appropriate conditions be considered. In this sense, this study proposes modeling and simulation of temporal and spatial profiles of the water content in apple slices during intermittent drying in two stages.

\section{Materials and Methods}

2.1. Sample preparation: The Fuji cv. apples (Malus domestica) were sanitized with water and then sliced ( $5 \mathrm{~mm}$ thick) using a slicer (ECO, Brazil). The slices were placed between two metallic screens to avoid deformation during the drying.

2.2. Convective dryer: The drying experiments were carried out using two identical tray dryer with forced convection as described by Filippin et al. (2018) [5]. The air flowed parallel to the samples. Dryer 1 was kept at 75,85 or $95^{\circ} \mathrm{C}$ and dryer 2 , at $60{ }^{\circ} \mathrm{C}$.

2.3. Drying tests: During the first stage of intermittent dryings, the trays were placed in dryer 1. After 45 minutes, they were removed from the dryer 1 and immediately inserted into the dryer 2, where remained until the samples reached constant weight. In both dryers the drying air velocity was $2 \mathrm{~m} \cdot \mathrm{s}^{-1}$. The samples were weighed successively during the drying using a semi-analytical balance (Gehaka, BK 4000, Brazil). 
2.4. Experimental determination of sample shrinkage: The shrinkage was described as a linear function of the moisture content on dry basis. The thickness was measured at each trial at the beginning and end of drying by using a micrometer screw (Mitutoyo, MDC-25SB, Japan).

2.5. Analytical methods: The total solids content of fresh and dried apple slices were gravimetrically determined in triplicate by drying in a vacuum oven at $60{ }^{\circ} \mathrm{C}$ and $10 \mathrm{kPa}$ to constant weight. The water activity of the samples was measured in triplicate at $25^{\circ} \mathrm{C}$ in a hygrometer (Aw sprint; Novasina, Switzerland).

2.6. Mathematical modeling: Considering that drying can be described by the falling-rate period and that liquid diffusion is the principal mass transfer mechanism, the drying kinetics were evaluated based on Fick's second law [7] presented in Eq. 1 in its modified form, in terms of the mass fractions (dry basis, d.b.). It was assumed a constant solids concentration. The slice was considered as a flat plate with mass flow along the thickness of the apple (zaxis).

$$
\frac{\partial \mathrm{X}}{\partial \mathrm{t}}=\mathrm{D}_{\mathrm{eff}} \frac{\partial^{2} \mathrm{X}}{\partial \mathrm{z}^{2}}
$$

where $\mathrm{X}$ is the mass fraction of water on a dry weight basis $\left(\mathrm{kg} \cdot \mathrm{kg}^{-1}\right) \mathrm{D}_{\text {eff }}$ represents the effective diffusivity $\left(\mathrm{m}^{2} \cdot \mathrm{s}^{-1}\right), \mathrm{z}$ is the thickness and $\mathrm{t}$ is the time (s).

Initial conditions for the first and second stage of the intermittent drying are presented in Eq. 2 and 3 , respectively.

$$
\begin{array}{l|l}
\mathrm{t}=0 & \mathrm{X}_{1}=\overline{\mathrm{X}}^{0} \\
\mathrm{X}_{2}=\mathrm{X}_{2}^{0}(\mathrm{z})
\end{array}
$$

where the sub index 1 and 2 represent the first and the second stage, respectively, and the super index 0 represents the initial condition. At the second stage, the initial water mass fraction is a function of de distance $z$, because there is a spatial distribution profile of water content in the sample at the end of the first stage.

Eqs. 4 and 5 represent the spatial conditions.

$$
\mathrm{z}= \pm \mathrm{L} / 2 \quad \mathrm{X}=\mathrm{X}^{\mathrm{eq}}
$$




$$
\mathrm{z}=0 \quad \frac{\partial \mathrm{X}}{\partial \mathrm{z}}=0
$$

where $\mathrm{L}$ is the initial thickness of the apple slice and $\mathrm{z}=0$ refers to the central position on the $\mathrm{z}$-axis (symmetry condition) and $\mathrm{X}^{\mathrm{eq}}$ is the water mass fraction in equilibrium. Eq. 4 and 5 were employed in both drying stages.

In this study, the thickness shrinkage was described by a linear equation as a function of moisture and, therefore, included in the Eq. 1

The parabolic partial differential equations were solved by finite differences method using MATLAB software (MathWorks Inc., Natick, Massachusetts, USA). The moisture profile generated in the first stage was the initial condition of the second stage. The effective diffusion coefficients $\left(\mathrm{D}_{\text {eff }}\right)$ were determined by minimizing the (relative) deviations between predicted and observed average water contents in the slices. For this, the predicted water profiles were integrated and compared with the observed values.

The estimated parameter $D_{\text {eff }}$ was evaluated based on the best fit using statistical indicators as such as the coefficient of determination of the fit $\left(\mathrm{R}^{2}\right)$, the mean relative error $(\mathrm{P} \%)$ and on the root mean square error (RMSE).

$$
\begin{aligned}
& \mathrm{P}(\%)=\frac{100}{\mathrm{~N}} \sum_{1}^{\mathrm{n}} \frac{\left|\mathrm{X}^{\mathrm{exp}}-\mathrm{X}^{\mathrm{cal}}\right|}{\mathrm{X}^{\exp }} \\
& \mathrm{RMSE}=\left[\frac{1}{\mathrm{~N}} \sum_{1}^{\mathrm{n}}\left(\mathrm{MR}^{\mathrm{cal}}-\mathrm{MR}^{\exp }\right)^{2}\right]^{\frac{1}{2}}
\end{aligned}
$$

where $\mathrm{X}^{\text {calc }}$ represents the water content on a dry basis, $\mathrm{X}^{\exp }$ is the experimental value, $\mathrm{MR}^{\exp }$ is the experimental moisture ratio, $\mathrm{MR}^{\text {calc }}$ the calculated moisture ratio and $\mathrm{N}$ represents the number of observations or residuals.

\section{Results and Discussion}

The moisture and water activity of the samples for the treatments are shown in Table 1.

Table 1. Moisture and water activity of the fresh and dried samples

\begin{tabular}{ccccc}
\hline \multirow{2}{*}{ Treat. } & \multicolumn{3}{c}{ Moisture } & $\mathrm{a}_{\mathrm{w}}$ \\
\cline { 2 - 5 } & Fresh sample & Dried Sample & Equilibrium & Dried sample \\
\hline T1 & $0.869 \pm 0.002$ & $0.047 \pm 0.001$ & $0.033 \pm 0.001$ & $0.275 \pm 0.016$ \\
T2 & $0.860 \pm 0.002$ & $0.043 \pm 0.001$ & $0.032 \pm 0.001$ & $0.237 \pm 0.013$ \\
T3 & $0.863 \pm 0.002$ & $0.050 \pm 0.001$ & $0.032 \pm 0.002$ & $0.248 \pm 0.016$ \\
\hline
\end{tabular}


The experimental curves of the intermittent drying are shown in Fig.1.

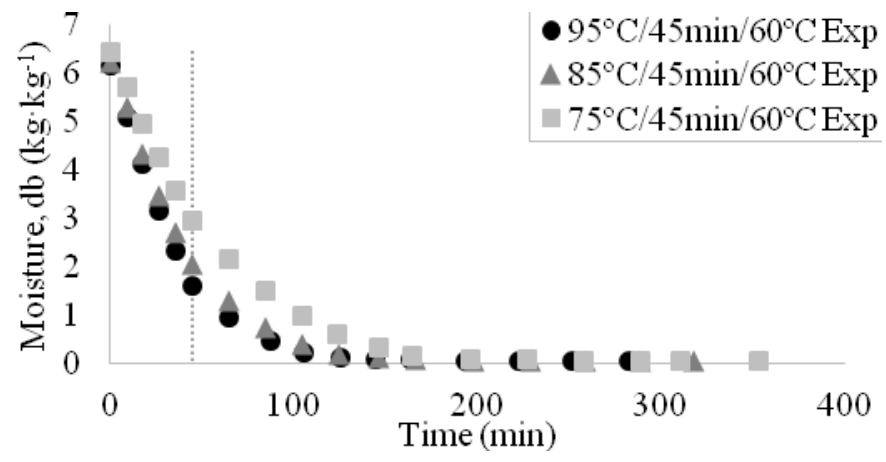

Fig 1. Experimental curves of the intermittent drying

It was observed that the intermittent drying curves exhibit a discontinuity between the first and second stages, indicated by the vertical dashed line. The relation between the drying rate and the air temperature is evidenced by the difference between the curves in the first stages, in which higher drying air temperature promoted a more pronounced slope of the curve. In addition, after $45 \mathrm{~min}$ at $75^{\circ} \mathrm{C}$, the sample average moisture reached $75 \%$ on wet basis (or 2.97, d.b.), while at $95^{\circ} \mathrm{C}$ the average moisture was $62 \%$ (1.63, d.b.).

Table 2 shows the effective diffusivity obtained at each stage of the intermittent drying treatments and the statistical parameters evaluated.

Table 2. Diffusion coefficients ( $\left.\mathrm{D}_{\mathrm{eff}}\right) \mathrm{R}^{2}, \mathbf{P}(\%)$ and $\mathrm{RMSE}$

\begin{tabular}{cccccc}
\hline Treatment & $\begin{array}{c}\mathrm{T} \\
\left({ }^{\circ} \mathrm{C}\right)\end{array}$ & $\begin{array}{c}\mathrm{D}_{\text {eff }} \times 10^{10} \\
\left(\mathrm{~m}^{2} \cdot \mathrm{s}^{-1}\right)\end{array}$ & $\mathrm{R}^{2}$ & $\mathrm{P}(\%)$ & $\mathrm{RMSE}$ \\
\hline \multirow{2}{*}{$\mathrm{T} 1$} & 95 & 7.00 & 0.990 & 3.1 & 0.032 \\
& 60 & 3.40 & 0.999 & 28.7 & 0.005 \\
$\mathrm{~T} 2$ & 85 & 5.90 & 0.992 & 2.3 & 0.027 \\
& 60 & 3.10 & 0.999 & 25.0 & 0.004 \\
\multirow{2}{*}{$\mathrm{T} 3$} & 75 & 4.50 & 0.985 & 2.8 & 0.034 \\
& 60 & 2.75 & 0.999 & 22.4 & 0.011 \\
\hline
\end{tabular}

The $\mathrm{P}(\%)$ values obtained in the second stage were higher than those obtained in the first stage and they were above $10 \%$, which is considered as a reference value [8]. However, since the $\mathrm{P}(\%)$ value is calculated as a relative residual, the error value is amplified as the moisture content decreases through the second stage of drying. The values of RMSE, a non-relative parameter, were satisfactory for both stages as well as the coefficient of determination $\left(\mathrm{R}^{2}\right)$, indicating that the proposed model presented a good fit to the experimental data.

Experimental and simulated curves are shown in Fig. 2. 


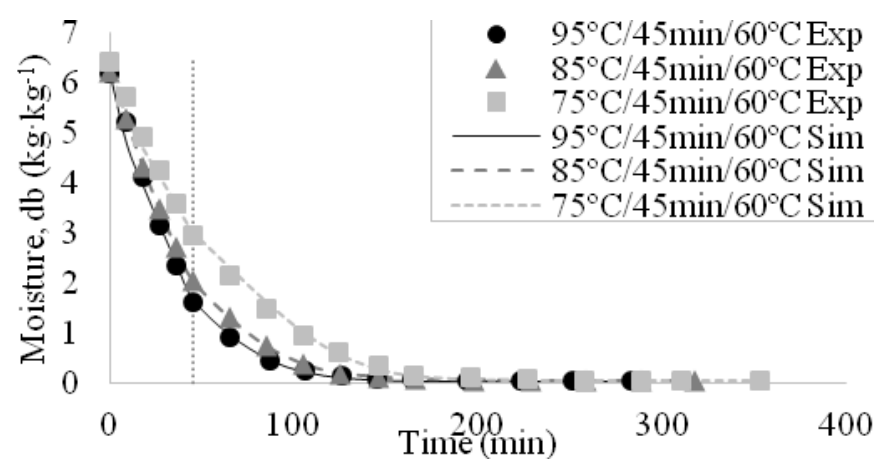

Fig. 2. Experimental (Exp) e simulated (Sim) drying curves

It is important to highlight that drive forces are not only related to mass concentration gradients, although this is the main driving force of the phenomenon [7]. Temperature gradients, which are more significant in the beginning of the process, will also influence the water transport [6]. However, in the case of a single-parameter model, $\mathrm{D}_{\text {eff }}$ encompasses all possible parameters that effectively influence the mass transport.

The effective diffusion coefficients of the first stage (Table 2) showed exponential temperature dependence, which was empirically represented by an Arrhenius type equation, as described in Eq. 8. This equation has been reported in the literature to describe the $D_{\text {eff }}$ as a function of the air-drying temperature $[9,10]$. For the first stage, the activation energy was $23.59 \mathrm{~kJ} \cdot \mathrm{mol}^{-1}\left(\mathrm{R}^{2}=0.987\right)$, as follows:

$$
\mathrm{D}_{\text {eff }}=1.57 \times 10^{-6} \exp ^{-23.59 / \mathrm{RT}}
$$

in which $D_{\text {eff }}$ assumes the value of $1.57 \times 10^{-6} \mathrm{~m}^{-2} \cdot \mathrm{s}^{-1}$ when the temperature $(\mathrm{T})$ tends to infinite and $\mathrm{R}$ is the universal gas constant in $\mathrm{kJ} \cdot \mathrm{mol}^{-1} \cdot \mathrm{K}^{-1}$.

Although the air-drying temperatures of the second stages were the same $\left(60^{\circ} \mathrm{C}\right)$, the $\mathrm{D}_{\text {eff }}$ values were different. Therefore, a dependence on the first stage air-drying temperature was found. The increase of $10^{\circ} \mathrm{C}$ in the first stage temperature led to an increase of about $11 \%$ in the $D_{\text {eff }}$ of the second stage. This result indicates that the first stage temperature contributed to the second stage efficiency, probably because of modifying the vegetable structure that would make the water exit easier in the later stage.

The drying has been represented in the literature through empirical models such as the Peleg, Page, Handerson and Pabis and Lewis and fundamental mathematical models [4,11]. Regarding the intermittent drying, some authors model the initial condition of subsequent stages by considering a homogeneous spatial distribution of the water $[9,12]$. This 
consideration is reasonable when tempering times are used between the stages, since this procedure provides redistribution of the water content in the solid during the holding time. Therefore, a moisture profile of the initial stage could be used to calculate the ideal tempering time required for the moisture to become homogeneous [13].

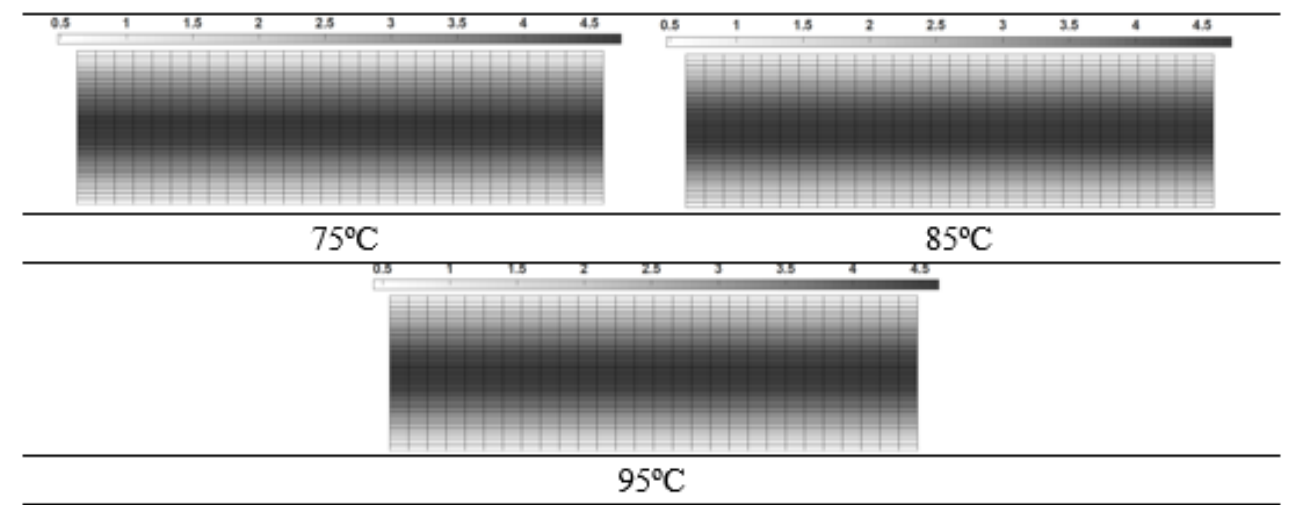

Fig. 3. Spatial distribution of water in the apple slice at the end of the first stage at 75,85 and $95^{\circ} \mathrm{C}$.

In the case of the thermal intermittence applied in this study, at the end of the first stage the profile of spatial water distribution was evident, as shown in Fig. 3. At the end of the first stage at $95^{\circ} \mathrm{C}$, the water content was about 9 times larger at the centre of the sample than at the surface, which highlights the need to consider the moisture profile in the initial condition of the second stage. Thus, the approximation of moisture profile to experimental mean moisture would be a misconception that could underestimate the $\mathrm{D}_{\text {eff }}$ values.

Consideration of the shrinkage in the model also contributed to the good fit of the model. In this study, it was assumed that only the thickness dimension varied. In fact, as variation of the radial dimension of the slices was small, the mass transfer area could be neglected without considerably affecting the accuracy of the model fitting.

\section{Conclusions}

The proposed diffusive model was appropriated to simulate water profiles during two-stage intermittent drying of deformable foods, since it presented a good fit to the experimental data. The effective diffusion coefficients found in the second stage depended on the first stage temperature.

\section{Acknowledgements}

FAPESP, Proc 2017/02808-6 and CNPq. 


\section{References}

[1] Mayor L, Sereno AM. Modelling shrinkage during convective drying of food materials: a review. J Food Eng 2004, 61, 373-386.

[2] Mujumdar AS, Law CL. Drying Technology: Trends and Applications in Postharvest Processing. Food and Bioprocess Technology 2010 3,843-852.

[3] Demarchi SM, Ruiz NAQ, Concellón A, Giner SA. Effect of temperature on hot-air drying rate and on retention of antioxidant capacity in apple leathers. Food Bioproducts Processing, 2013, 91, 310-18.

[4] Kumar, C.; Karin, M. A.; Joardder, M. Intermittent Drying of Food Products: A Critical Review. Journal of Food Engineering, 2014, 121, 48-57.

[5] Filippin, A.P.; Molina Filho, L.; Fadel, V.; Mauro M.A. Thermal intermittent drying of apples and its effects on energy consumption. Drying Technology 2018. https://doi.org/10.1080/07373937.2017.1421549

[6] Treybal, R. E. Mass Transfer Operations; McGraw-Hill Book Co: Singapore, 1980.

[7] Crank, J. The Mathematics of Diffusion; Claredon Press:Oxford, 1975.

[8] Lomauro, C. J.; Bakshi, A. S.; Labuza, T. P. Evaluation of Food Moisture Sorption Isotherm Equations. Part I: Fruit, Vegetables and Meat Product. Food Science and Technology (LWT), 1985, 18(2), 111-117.

[9] Vaquiro, H. A.; Clemente, G.; Garcia-Perez, J. V.;Mulet, A., Bon, J. Enthalpy-Driven Optimization of Intermittent Drying of Mangifera indica L. Chemical Engineering Research and Design, 2009, 87(7), 885-898.

[10]Iguaz, A.; San Martín, M. B.; Maté, J. I.; Fernández, T.; Vírseda, P. “Modelling effective moisture diffusivity of rough rice (Lido cultivar) at low drying temperatures”, Journal of Food Engineering 2003, 59(2), 253-258.

[11] Cihan, A.; Kahveci, K.; Hacihafizoğlu, O. Modelling of Intermittent Drying of Thin Layer Rough Rice. Journal of Food Engineering, 2007, 79(1), 293-298.

[12] Silva, V.; Figueiredo, A. R.; Costa, J. J.; Guiné, R. P. F. Experimental and Mathematical Study of the Discontinuous Drying Kinetics of Pears. J. Food Eng. 2014,134, 30-36.

[13] Carmo, J.E.F.; Lima, A.G.B.; Silva, C.J. “Continuous and Intermittent Drying (Tempering) of Oblate Spheroidal Bodies: Modeling and Simulation.” International Journal of Food Engineering 2012, 8(3), 1556-3758. 